\title{
IJCIT
}

(Indonesian Journal on Computer and Information Technology) Journal Homepage: http://ejournal.bsi.ac.id/ejurnal/index.php/ijcit

\section{Perencanaan Strategis Sistem Informasi Dan Teknologi Informasi Pada PT. Matahari Department Store TBK.}

\author{
Chandra Indira Septiarani ${ }^{1}$, Audi Ramadhan ${ }^{2}$, Achmad Fauzi Saputra ${ }^{3}$, Nita Yalina ${ }^{4}$ \\ ${ }^{1,2,3}$ Sistem Informasi, UIN Sunan Ampel Surabaya \\ Surabaya, Indonesia \\ e-mail: cisrani3@gmail.com¹, audiramadhan29@gmail.com², saputrafauzi1999@gmail.com³, \\ nitayalina@uinsby.ac.id ${ }^{4}$
}

\begin{abstract}
A B S T R A K
PT. Matahari Department Store Tbk. adalah sebuah perusahaan ritel di Indonesia yang menawarkan berbagai produk fashion dan kosmetik untuk berbagai kalangan. Sampai saat ini, PT. Matahari Department Store Tbk membutuhkan maintenance perencanaan strategis sistem informasi untuk mengikuti tren pasar. Sehingga hal tersebut menjadi kesenjangan penulisan penelitian ini. penelitian ini bertujuan untuk merancang dan merencanakan teknologi strategis yang dapat digunakan PT. Matahari Department Store untuk meningkatkan efensiensi dan efektifitas operasional dan proses bisnisnya dalam meningkatkan laba. Metode yang digunakan dalam penelitian perencanaan strategis sistem informasi pada PT. Matahari Department Store Tbk. adalah menggunakan metode Ward \& Peppard. Hasil dari penelitian ini adalah rekomendasi sistem informasi yang memungkinkan meningkatkan efisiensi dan efektifitas proses bisnis PT. Matahari Department Store Tbk. seperti Digital Marketing, Aplikasi Digital Signature dan Kuitansi Pegawai, Sistem Pendukung Keputusan Ukuran Baju, Sistem Informasi Integrasi Market Place, Sistem Informasi Integrasi Rantai Pasok, Sistem Pendukung Keputusan Tren Fashion, Aplikasi Quality Control dan Sistem Informasi Kepatuhan dengan rencana implementasi selama 5 tahun. Dengan adanya penelitian ini diharapkan dapat meningkatkan efisiensi dan efektifitas proses bisnis PT. Matahari Department Store Tbk. Katakunci: perencanaan strategis sistem informasi, PT. Matahari Department Store Tbk., ward \& peppard
\end{abstract}

\section{A BSTRACTS}

PT. Matahari Department Store Tbk. is a retail company in Indonesia that offers a variety of fashion and cosmetic products for various groups. Until now, PT. Matahari Department Store Tbk requires maintenance of information system strategic planning to keep up with market trends. So that this is a gap in the writing of this study. This study aims to design and plan strategic technology that can be used by PT. Matahari Department Store to improve the efficiency and effectiveness of its operations and business processes in increasing profits. The method used in the strategic planning research of information systems at PT. Matahari Department Store Tbk. is to use the Ward \& Peppard method. The results of this study are recommendations for information systems that allow increasing the efficiency and effectiveness of PT. Matahari Department Store Tbk. such as Digital Marketing, Digital Signature and Employee Receipt Applications, Dress Size Decision Support Systems, Market Place Integration Information Systems, Supply Chain Integration Information Systems, Fashion Trend Decision Support Systems, Quality Control Applications and Compliance Information Systems with a 5-year implementation plan. With this research, it is hoped that the efficiency and effectiveness of the business processes of PT. Matahari Department Store Tbk.

Keywords: information system strategic planning, PT. Matahari Department Store Tbk., ward \& peppard 


\section{PENDAHULUAN}

Seiring dengan berkembangnya jaman, semakin meningkat juga perkembangan dalam bidang teknologi informasi. Namun, kebanyakan perusahaan lebih memilih untuk menggunakan teknologi yang dibutuhkan untuk operasional saat ini tanpa adanya perencanaan jangka panjang untuk mendukung potensi bisnis di masa depan. Hal ini terjadi karena kurangnya pemahaman mengenai pentingnya perkembangan teknologi khususnya penerapan sistem informasi dalam sebuah perusahaan. Tidak jarang pula suatu perusahaan tidak merasakan manfaat dari penggunaan sistem informasi atau perkembanga teknologi dalam perusahaannya. Hal ini disebabkan karena buruknya proses analisis sistem informasi yang dilakukan sebelum menerapkan sistem informasi atau menerapkan perkembangan teknologi dalam perusahaan. Selain itu, perusahaan juga tidak terlalu memperhatikan strategi dalam proses bisnisnya, sehingga penerapan sistem informasi atau penerapan perkembangan teknologi tidak sesuai dengan kondisi, kebutuhan, dan strategi perusahaan. Proses perencanaan sistem informasi sebelum penerapan sistem informasi sangatlah penting. Oleh sebab itu sebuah perusahaan perlu menggunakan perencanaan strategis sistem informasi untuk mengetahui secara jelas strategistrategi yang akan digunakan dalam sebuah perusahaan, hingga nantinya dihasilkan sebuah sistem yang berisi sejumlah alternatif teknologi informasi sesuai dengan keadaan perusahaan.

Penelitian sebelumnya pernah dilakukan oleh Setiawan pada objek yang berbeda namun dengan metode yang sama yakni pada PT. FM Global Logistics dengan metode Ward \& Peppard (Setiawan, 2016). Alat yang digunakan pada penelitian tersebut adalah Five Force Model Porter, Value Chain Analysis, SWOT, PEST dan McFarlan Strategic Grid. Hasil akhir dari penelitian ini adalah usulan perbaikan dan pengembangan sistem informasi dan teknologi informasi PT. FM Global Logistics dimasa mendatang untuk mengantisipasi persaingan dalam industri. Selain itu, Lah, Rahardja \& Sitokdana pada 2019 melakukan sebuah penelitan menggunakan metode Ward \& Peppard pada PT. Serasi Autoraya yang bergerak di bidang layanan transportasi (Lah, Rahardja and Sitokdana, 2019). Penelitian ini menggunakan beberapa alat yang digunakan untuk menganalisis seperti SWOT, Value Chain Analysis dan McFarlan Strategic Grid. Hasil dari penelitian ini menghasilkan sebuah rekomendasi untuk dikembangkan diantarnya Pengembangan Website Trac, Pengembangan aplikasi SAP, Pengembangan Aplikasi sistem infromasi layanan pelanggan, Aplikasi sistem infromasi aset dan Pengembangan Sistem Informasi Eksekutif dengan harapan untuk memberikan kejelasan arah dan mendorong perusahaan untuk terus berkembang baik dari aspek SDM SI dan pengembangan aplikasi portofolio yang akan mendukung kelangsungan proses bisnis di PT.Serasi Autoraya. Selanjutnya Himawan \& Astuti juga melakukan penelitian serupa pada Hotel Grand Kanaya Baturraden dengan menggunakan metodologi Ward \& Peppard (Himawan and Astuti, 2017). Analisis - analisis yang digunakan pada penelitian ini adalah CSF, SWOT, PEST, Value Chain Analysis dan McFarlan Strategic Grid dimana hasil penelitian ini adalah usulan berupa website profil Grand Kanaya Baturraden, data warehouse, sistem informasi manajemen hotel, sistem informasi kepegawaian, sistem informasi penerimaan tamu, sistem informasi keuangan hotel sebagai media pemasaran dan pelayanan pada Hotel Grand Kanaya Baturraden.

PT. Matahari Department Store Tbk. adalah perusahaan yang sudah lama didirikan, yaitu sejak tahun 1958. Perusahaan ini membutuhkan strategi perusahaan yang tepat dan baik dalam strategi bisnisnya ataupun strategi sistem informasi dan teknologi informasinya. Dengan demikian perusahaan dapat bertahan ataupun bersaing dengan perusahaan-perusahaan ritel lain yang telah lama berdiri sebelum perusahaan ini maupun perusahaan-perusahaan baru yang sudah mampu menyaingi perusahaan ini. Oleh sebab itu akan dilakukan maintenance perencanaan strategis sistem informasi agar dapat mengikuti tren pasar dengan menggunakan metode Ward and Peppard. Kemudian dari berbagai alternatif yang ada di dalam sebuah sistem akan ditentukan urutan prioritas alternatif yang harus diwujudkan terlebih dahulu berdasarkan urutan kepentingannya atau besarnya dampak yang diberikan kepada perusahaan.

Analisis-analisis yang digunakan pada penelitian ini adalah 1) SWOT. Analisis SWOT terdiri dari Strengths, Weakness, Opportunities, dan Threats. Analisis SWOT digunakan sebagai acuan untuk menganalisa kondisi dari sebuah organisasi yang sedang dihadapi. Tujuan dari 
analisis SWOT adalah untuk mengetahui langkah strategis yang dapat dilakukan untuk mencapai tujuan organisasi, menghindari serta meminimalkan hal yang tidak diinginkan (Gazella, Darwiyanto and Wisudiawan, 2016; Gurel and Tat, 2017); 2) PEST. Analisis PEST terdiri dari Political, Economic, Social dan Technological yang mana berguna untuk mendeskripsikan dan menjelaskan kerangka kerja faktor lingkungan makro yang digunakan dalam komponen pemindaian lingkungan manajemen strategis (Gupta, 2013; Sammut-Bonnici and Galea, 2015). Sehingga dengan adanya analisis PEST, manajemen dapat terbantu menyelaraskan strategi bisnis dengan kondisi lingkungan luar yang ada; 3) Value Chain Analysis, digunakan untuk memetakan seluruh proses kerja yang terjadi dalam organisasi menjadi dua kategori aktivitas, yaitu aktivitas utama dan aktivitas pendukung (Ari Wedhasmara, 2009). Aktivitas utama yaitu aktivitas yang berkaitan dengan penciptaan fisik produk, penjualan dan distribusinya ke para pembeli, dan layanan setelah penjualan sedangkan aktivitas pendukung yaitu aktivitas yang menyediakan dukungan yang diperlukan bagi berlangsungnya aktivitas utama seperti teknologi, sumber daya manusia dan fungsi berbagai perusahaan secara luas; 4) Balance scorecard dapat didefinisikan sebagai seperangkat ukuran tentang bisnis, termasuk ukuran keuangan yang memberi segala informasi mengenai hasil tindakan yang sudah diambil, melengkapi langkah-langkah keuangan dengan langkah-langkah operasional pada kepuasan pelanggan, proses internal, inovasi organisasi dan peningkatan ukuran kegiatan operasional, dan segala aktivitas yang digunakan sebagai pendorong kinerja keuangan di masa yang akan datang (Yulianto, 2018); 5) Analisis five porter force bertujuan untuk menganalisis dan mengevaluasi struktur lingkungan dan ancaman dalam persaingan dari suatu bisnis. Selain itu, terdapat empat pertimbangan dari Porter's Five Force Analysis yang digunakan untuk menganalisis sebuah persaingan bisnis yakni threat of new entrants (ancaman dari pendatang baru), bargaining power of buyers (daya tawar pembeli), threat of subtitutes (ancaman produk pengganti) dan bargaining power of suppliers (daya tawar pemasok) (Porter, 2008); 6) McFarlan Strategic Grid. Analisis McFarlan Strategic Grid terdiri dari empat kuadran yakni key operational, support, strategy dan high potential dimana analisis McFarlan Strategic Grid itu sendiri berfungsi untuk pengelompokkan pengembangan sistem informasi yang dibutuhkan di masa depan (Hakim, 2017).

Dengan demikian penelitian ini bertujuan untuk merancang dan merencanakan teknologi strategis yang dapat digunakan PT. Matahari Department Store untuk meningkatkan efensiensi dan efektifitas operasional dan proses bisnisnya dalam meningkatkan laba.

\section{METODE PENELITIAN}

Penelitian ini dilakukan pada PT. Matahari Department Store Tbk, dengan menggunakan metode Ward \& Peppard. Berikut ini adalah kerangka konseptual dari metodologi Ward \& Peppard (Ward and Peppard, 2002):

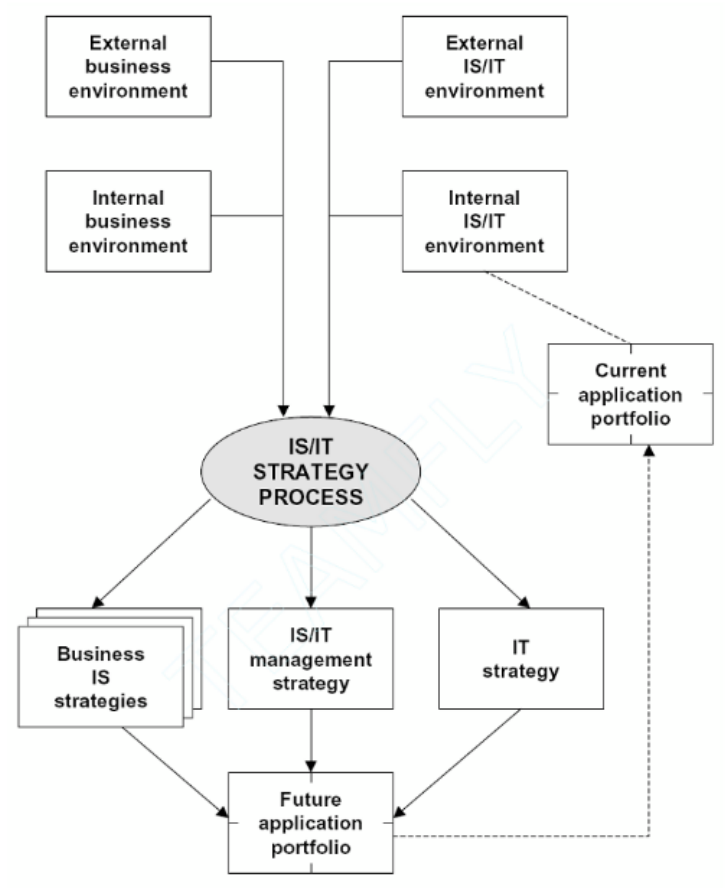

Gambar 1. Metode Ward \& Peppard

Berikut ini adalah penjelasan langkah langkah metode Ward \& Peppard yang telah dijelaskan seperti yang telah tertera pada gambar 1 (Septiana, 2017):

Tahapan Masukan:

a. Analisis Lingkungan bisnis internal: Strategi Bisnis sekarang, tujuan (objektif), sumber daya, proses, dan kebudayaan serta nilai dari suatu bisnis.

b. Analisis Lingkungan bisnis eksternal: ekonomi, lingkungan industri, iklim persaingan dimana organisasi beroperasi.

c. Analisis Lingkungan SI/TI internal: perspektif $\mathrm{SI} / \mathrm{TI}$ sekarang di bisnis, kematangannya, 
ruang lingkup dan kontribusi bisnis, skill, sumber daya dan infrastruktur teknologi. Portofolio aplikasi dari sistem yang ada sekarang dan sistem yang sedang dikembangkan, atau sudah dianggarkan tetapi belum selesai juga merupakan bagian dari lingkungan $\mathrm{SI} / \mathrm{TI}$ internal.

d. Analisis Lingkungan SI/TI eksternal: tren teknologi dan kesempatan serta kegunaan yang dihasilkan oleh SI/TI pihak lain, terutama customer, pesaing dan supplier.

Tahapan keluaran yaitu:

a. Strategi Bisnis SI: bagaimana setiap unit atau fungsi akan mengembangkan SI/TI dalam mencapai tujuan (objektif) bisnisnya.

b. Strategi manajemen SI/TI: elemen-elemen yang lazim dari strategi yang diterapkan organisasi secara keseluruhan, menjamin kebijakan konsisten yang dibutuhkan.

c. Strategi SI/TI: kebijakan dan strategi untuk menajemen teknologi dan ahli sumber daya.

Selain itu juga terdapat beberapa metode analisis yang akan digunakan dalam penelitian ini seperti analisis SWOT, PEST, Balance Scorecard, Porter's Five Force Analysis, Value Chain Analysis dan McFarlan Strategic Grid.

\section{HASIL DAN PEMBAHASAN}

\subsection{Gambaran Umum Perusahaan}

Matahari Department Store adalah sebuah perusahaan ritel di Indonesia yang merupakan pemilik dari jaringan toserba Matahari. Saat ini, Matahari Department Store merupakan salah satu anak perusahaan dari Lippo Group. Per kuartal pertama tahun 2017, Matahari Department Store sudah mempunyai 151 gerai di lebih dari 60 kota di Indonesia. Kini, menyesuaikan dengan kondisi zaman dengan maraknya e-commerce di Indonesia, Matahari membuka gerai online dengan alamat MatahariMall.com. Namun, web ini diganti dengan Matahari.com. Pada dasarnya Matahari Department Store memiliki tujuan filosofis sendiri dalam proses bisnisnya seperti (1) Matahari berusaha menciptakan, tingkat hidup yang lebih baik bagi seluruh karyawan, (2) Matahari berusaha menciptakan, tempat kerja yang aman, nyaman, tentram dan sejahtera, sebagai pancaran cita - cita karyawan, (3) Matahari berusaha menciptakan, system organisasi operasional terpadu demi masa depan perusahaan dan karyawan, atas dasar efisiensi kerja yang maksimal, (4) Matahari berusaha mendidik, melatih dan mengembangkan seluruh karyawan yang merata, tanpa membedakan tradisi, agama, asal keturunan, sadar akan tugas dan kewajiban, menjunjung tinggi tujuan perusahaan sebagai perekonomian bangsa dan (5) Matahari berharap atas dasar sinkronasi, saling percaya mempercayai, hormat menghormati, kerjasama yang baik dengan azas kekeluargaan, untuk mencapai kemajuan yang kekal dan abadi. Selain itu, Matahari Department Store juga memiliki visi dan misi. Berikut ini adalah visi dan misi Matahari Department Store: Visi: Semua orang Indonesia dapat tampil menarik dan nyaman.

Misi: Menyediakan berbagai kebutuhan fashion berkualitas dan terjangkau bagi para pelanggan dengan suasana yang ramah, sehingga dapat memberikan pengalaman belanja yang menyenangkan dan meningkatkan kualitas hidup secara keseluruhan.

\subsection{Analisis Lingkungan Internal/Eksternal Bisnis}

Analisis SWOT yang dilakukan pada PT. Matahari Department Store Tbk. Mencakup tentang kekuatan (strength), kelemahan (weakness), peluang (opportunities) dan Ancaman (treath) yang mana kekuatan dan kelemahan yang ada didalam perusahaan sedangkan peluang dan ancaman adalah faktor yang berasal dari luar perusahaan. Berikut ini adalah tabel analisis SWOT PT. Matahari Department Store Tbk. Untuk memetakan faktor internal dan eksternal bisnis dapat dilihat pada tabel 1.

Selanjutnya seluruh proses bisnis dari PT. Matahari Department Store dipetakan dengan menggunakan analisis value chain. Analisis value chain dibagi menjadi 2 yaitu aktivitas utama dan aktivitas pendukung. Hasil analisis value chain dari PT. Matahari Department Store Tbk dapat dilihat pada gambar 2 .

Berdasarkan gambar 2, proses bisnis pada PT. Matahari Department Store Tbk. dapat dirincikan sebagai berikut:

1. Aktivitas Utama

Inbound logistic: Pencatatan penerimaan ke gudang dan penerimaan produk/barang

Operation: Pengecekan kualitas barang dan pengecekan dokumen inventaris

Outbond logistic: Virtual merchandising

Marketing and sales: Promosi, bazaar dan strategi B2B

Service: Customer service dan kasir

2. Aktivitas Pendukung

Firm infrastructure: Legal, manajemen keuangan, rantai pasok, sumber daya 
manusia, manajemen properti dan perencanaan toko, pemasaran, reputasi.

Human Resource Management: Rekrutmen, training, tour, penggajian dan kompensasi, pemberhentian

Teknologi: Scanner, sistem informasi, web profil, e-commerce web dan android, android khusus

Procurement: Konsinyasi, direct selling, rantai pasok
Berikutnya adalah analisis lingkungan bisnis eksternal pada PT. Matahari Department Store Tbk. Analisis yang digunakan untuk menganalisis faktor bisnis eksternal pada penelitian ini menggunakan analisis PEST yang terdiri dari 4 indikator, yakni politik, ekonomi, sosial dan teknologi. Hasil analisis lingkungan bisnis eksternal pada PT. Matahari Department Store Tbk dapat dilihat pada tabel 2.

Tabel 1. Analisis SWOT PT. Matahari Department Store Tbk.

\begin{tabular}{ll}
\hline Dimensi & Deskripsi \\
\hline Strength & 1. Perusahaan memiliki strategi pemasaran yang menarik dengan banyak menerbitkan \\
promo & 2. Perusahaan memiliki reputasi sebagai perusahaan retail lokal terbaik di Indonesia \\
3. Perusahaan mengikuti perkembangan teknologi guna efisiensi operasional \\
4. Perusahaan menerapkan sistem direct purchase dan consignment, sehingga dapat \\
menekan biaya rantai pasok dan harga yang ditawarkan kepada pelanggan menjadi \\
lebih murah \\
5. Memiliki program membership yang bekerja sama dengan OVo dan BCA \\
6. Perusahaan telah melantai di Bursa Efek Indonesia (LPPF) \\
7. Perusahaan sudah memiliki toko online independen \\
1. Perusahaan tidak dapat mengikuti perkembangan desain masa kini dikarenakan \\
desain produk tidak didesain langsung oleh perusahaan \\
2. Kurang responsif untuk beradaptasi terhadap pesaing \\
3. Kurangnya loyalitas pelanggan \\
4. Pihak manajemen kurang up to date terhadap masalah yang terjadi di lapangan \\
5. Jumlah pekerja terlalu banyak \\
1. Pangsa bisnis ritel di Indonesia yang cukup besar dan semakin meningkat \\
2. Banyaknya kota/kabupaten di Indonesia yang belum tersentuh department store \\
3. Tumbuhnya kesadaran masyarakat akan pentingnya akan fashion \\
4. Munculnya Malldan pusat perbelanjaan baru \\
5. Daya beli masyarakat terus meningkat \\
1. Adanya persaingan dengan toko ritel asing yang sedang menjamur dan naik daun di \\
Indonesia \\
2. Beberapa brand mulai mendirikan gerai sendiri \\
3. Minat masyarakat terhadap ritel brand local menurun \\
4. Masyarakat lebih membeli produk fashion secara online (eCommerce)
\end{tabular}

\begin{tabular}{|c|c|c|c|c|}
\hline \multicolumn{5}{|c|}{$\begin{array}{l}\text { Firm Infrastructure : Legal, manajemen keuangan, rantai pasok, SDM , manajemen } \\
\text { properti dan perencanaan toko, pemasaran, reputasi }\end{array}$} \\
\hline \multicolumn{5}{|c|}{$\begin{array}{l}\text { Human Resource Management ; Rekrutmen, training, tour, penggajian dan } \\
\text { kompensasi, pemberhentian }\end{array}$} \\
\hline \multicolumn{5}{|c|}{$\begin{array}{l}\text { Technology Development : Scanner, SI, web profil, e-commerce web dan android, } \\
\text { android khusus }\end{array}$} \\
\hline \multicolumn{5}{|c|}{ Procurement : Konsinyasi, direct selling, rantai pasok } \\
\hline $\begin{array}{l}\text { Inbound Logistic: } \\
\text { Pencatatan } \\
\text { penerimaan ke } \\
\text { gudang, } \\
\text { penerimaan } \\
\text { produk } \\
\end{array}$ & $\begin{array}{c}\text { Operation: } \\
\text { Pengecekan } \\
\text { kualitas barang, } \\
\text { pengecekan } \\
\text { dokumen } \\
\text { inventory } \\
\end{array}$ & $\begin{array}{l}\text { Outbond } \\
\text { Logistic: } \\
\text { Virtual } \\
\text { merchandising }\end{array}$ & \begin{tabular}{|c} 
Marketing \& \\
Sales : Promosi, \\
Bazaar, Strategi \\
B2B
\end{tabular} & $\begin{array}{c}\text { Service: } \\
\text { Customer } \\
\text { Service, Kasir }\end{array}$ \\
\hline
\end{tabular}

Gambar 2. Value Chain Analysis 
Tabel 2. Analisis PEST PT. Matahari Department Store Tbk.

\begin{tabular}{|c|c|}
\hline Dimensi & Deskripsi \\
\hline Politik & $\begin{array}{l}\text { 1. Peraturan Pemerintah Republik Indonesia Nomor } 24 \text { Tahun } 2018 \text { tentang Pelayanan } \\
\text { Izin Berusaha Terintegrasi secara Elektronik } \\
\text { 2. UU Nomor } 8 \text { Tahun } 1995 \text { tentang Pasar Modal dan peraturan pelaksanaannya } \\
\text { 3. UU Nomor } 40 \text { Tahun } 2007 \text { tentang Perseroan Terbatas } \\
\text { 4. UU Nomor } 13 \text { Tahun } 2003 \text { tentang Ketenagakerjaan } \\
\text { 5. Instruksi Presiden untuk membeli produk lokal }\end{array}$ \\
\hline Ekonomi & $\begin{array}{l}\text { 1. Daya beli masyarakat terhadap sandang relatif meningkat } \\
\text { 2. Pertumbuhan ekonomi Indonesia meningkat secara konsisten } \\
\text { 3. Inflasi di Indonesia relative rendah }(3.5 \%( \pm 1 \%))\end{array}$ \\
\hline Sosial & $\begin{array}{l}\text { 1. Kesadaran masyarakat akan pentingnya memilih fashion sesuai syariat agama } \\
\text { 2. Banyak masyarakat lebih memilih untuk membeli produk di toko online }\end{array}$ \\
\hline Teknologi & 1. Perkembangan teknologi yang berkembang sangat pesat \\
\hline
\end{tabular}

Langkah selanjutnya adalah menganalisis persaingan bisnis PT. Matahari Department Store Tbk. menggunakan Porter's Five Force Analysis dengan memperhatikan ancaman produk pengganti dan pendatang baru serta daya tawar suplier dan pembeli. Hasil analisis Five Porter dari PT. Matahari Department Store Tbk. dapat dilihat pada tabel 3.

Tabel 3. Analisis Porter's Five Forces Model PT. Matahari Department Store Tbk

\begin{tabular}{|c|c|c|}
\hline Dimensi & Contoh & Solusi \\
\hline $\begin{array}{l}\text { Threat of new } \\
\text { entrants }\end{array}$ & Uniqlo, Zara, H\&M & $\begin{array}{l}\text { Meningkatkan customer loyalty agar konsumen } \\
\text { tidak memilih pesaing baru }\end{array}$ \\
\hline $\begin{array}{l}\text { Bargaining power of } \\
\text { buyers }\end{array}$ & $\begin{array}{l}\text { Trader, B2B, } \\
\text { Masyarakat umum }\end{array}$ & $\begin{array}{l}\text { Meningkatkan customer satisfaction melalui } \\
\text { kualitas pelayanan, produk dan harga }\end{array}$ \\
\hline Threat of subtitutes & $\begin{array}{l}\text { Tokopedia, Bukalapak, } \\
\text { Lazada }\end{array}$ & $\begin{array}{l}\text { Mengadopsi teknologi e-commerce modern agar } \\
\text { web e-commerce yang dimiliki saat ini lebih } \\
\text { efektif dan efisien }\end{array}$ \\
\hline $\begin{array}{l}\text { Bargaining power of } \\
\text { suppliers }\end{array}$ & $\begin{array}{l}\text { Nevada, Adidas, Cole, } \\
\text { Fladeo, Kickers }\end{array}$ & $\begin{array}{l}\text { Menigkatkan dan menambah relasi dengan } \\
\text { supplier }\end{array}$ \\
\hline $\begin{array}{l}\text { Rivalry among } \\
\text { existing competitors }\end{array}$ & Ramayana, Sogo & $\begin{array}{l}\text { Meningkatkan intensitas pemasaran dan } \\
\text { customer satisfaction }\end{array}$ \\
\hline
\end{tabular}

\subsection{Analisis Lingkungan Internal SI/TI dan Eksternal SI/TI}

Pada tahap ini hasil wawancara dan observasi di PT. Matahari Department Store Tbk. Mendeskripsikan kondisi SI/TI perusahaan yang ada pada saat ini dengan matriks McFarlan Strategic Grid yang terdiri dari 4 kuadran, Kondisi $\mathrm{SI} / \mathrm{TI}$ yang ada pada PT. Matahari Department Store Tbk. saat ini dapat dilihat pada tabel 4.

Tabel 4. McFarlan Strategic Grid untuk SI PT. Matahari Department Store yang Sudah Ada

\begin{tabular}{ll}
\hline Strategic & High Potential \\
\hline QR Code Payment & - \\
\hline Key Operational & Support \\
\hline 1. Sistem Informasi Kasir & Web Perusahaan \\
2. Sistem Informasi Kepegawaian & \\
3. Sistem Informasi Keuangan & \\
4. Aplikasi Administrasi Toko-Gudang & \\
5. Web e-commerce & \\
6. Absen Fingerprint & \\
Scanner &
\end{tabular}


Dengan adanya perkembangan kondisi eksternal SI/TI saat ini, terdapat masukan dari hasil analisis pada PT. Matahari Department Store Tbk. Berupa tren user interface (UI), database, server dan hardware.

\subsection{Strategi Bisnis SI}

Tahap selanjutnya adalah mengidentifikasi target-target perusahaan yang dinilai dapat diisi kesenjangannya dengan mengimplementasikan teknologi. Target-target tersebut disegmentasikan dengan menggunakan analisis Balanced Scorecard. Hasil analisis Balanced Scorecard pada PT. Matahari Department Store Tbk. dan solusi dengan teknologinya dapat dilihat pada tabel 5 .

Tabel 5. Balanced Scorecard dan Usulan Sistem untuk PT. Matahari Department Store

\begin{tabular}{|c|c|}
\hline Financial & Solusi SI \\
\hline $\begin{array}{l}\text { 1. Meningkatkan penjualan offline dan } \\
\text { online }\end{array}$ & $\begin{array}{l}\text { 1. Meningkatkan efektifitas pelayanan pada kasir } \\
\text { dan eCommerce } \\
\text { 2. Memanfaatkan marketing digital di media sosial } \\
\text { 3. Bekerjasama dengan marketplace }\end{array}$ \\
\hline Customers & Solusi SI \\
\hline $\begin{array}{l}\text { 1. Memberikan promo yang menarik } \\
\text { 2. Memberikan pelayanan yang terbaik }\end{array}$ & $\begin{array}{l}\text { 1. Membantu memberi arahan tentang fashion yang } \\
\text { cocok pada setiap customer } \\
\text { 2. Meningkatkan kualitas produk dan pelayanan }\end{array}$ \\
\hline Internal Business & Solusi SI \\
\hline $\begin{array}{l}\text { 1. Meningkatkan efisiensi transaksi } \\
\text { 2. Menjalankan SOP dengan baik } \\
\text { 3. Meningkatkan keamanan dari } \\
\text { pencurian/kehilangan barang }\end{array}$ & $\begin{array}{l}\text { 1. Mengawasi pekerjaan setiap divisi } \\
\text { Memangkas proses administrasi yang kurang } \\
\text { diperlukan }\end{array}$ \\
\hline Learning \& Growth & Solusi SI \\
\hline $\begin{array}{l}\text { 1. Memberikan bonus kepada pegawai } \\
\text { dengan penjualan terbanyak } \\
\text { 2. Meningkatkan jumlah cabang di kota - } \\
\text { kota yang ada di Indonesia } \\
\text { 3. Menambah jumlah partner bisnis }\end{array}$ & $\begin{array}{l}\text { 1. Memanfaatkan data yang ada sebagai peramalan } \\
\text { penjualan di masa mendatang } \\
\text { 2. Menigkatkan jaringan partner bisnis } \\
\text { 3. Mengidentifikasi setiap proses penjualan }\end{array}$ \\
\hline
\end{tabular}

Berdasarkan hasil penjabaran strategi $\mathrm{SI} / \mathrm{TI}$ dan strategi bisnis, maka terciptalah aplikasi portofolio dengan prioritas dan blueprint strategis SI/TI yang berpedoman pada Mc Farlan Strategic Grid. Usulan sistem informasi dan teknologi yang memungkinkan untuk meningkatkan efensiensi dan efektifitas operasional dan proses bisnis PT. Matahari Department Store Tbk. dalam meningkatkan laba dapat dilihat pada tabel 6 .

Tabel 6. McFarlan Strategic Grid untuk SI PT. Matahari Department Store di Masa Mendatang

\begin{tabular}{|c|c|}
\hline Strategic & High Potential \\
\hline 1. Digital Marketing (New) & 1. Sistem Informasi Kepatuhan (New) \\
\hline 2. Sistem Pendukung Keputusan Ukuran & 2. Sistem Informasi Integrasi Rantai Pasok (New) \\
\hline Baju (New) & 3. Sistem Informasi Integrasi Market Place (New) \\
\hline $\begin{array}{l}\text { 3. Sistem Pendukung Keputusan Tren } \\
\text { Fashion (New) }\end{array}$ & $\begin{array}{l}\text { 4. Aplikasi Digital Signature dan Kuitansi Pegawai } \\
\text { (New) }\end{array}$ \\
\hline 4. QR Code Payment & \\
\hline 5. Aplikasi Quality Control (New) & \\
\hline Key Operational & Support \\
\hline 1. Sistem Informasi Kasir & Web Perusahaan \\
\hline 2. Sistem Informasi Kepegawaian & \\
\hline 3. Sistem Informasi Keuangan & \\
\hline 4. Aplikasi Administrasi Toko-Gudang & \\
\hline 5. Web e-commerce & \\
\hline 6. Absen Fingerprint & \\
\hline 7. Scanner & \\
\hline
\end{tabular}




\subsection{Strategi Manajemen SI/TI}

Divisi teknologi informasi pada PT. Matahari Department Store Tbk. dinilai kurang efektif, hal tersebut dikarenakan divisi TI selalu berada dibawah divisi lainnya yang mana bertugas untuk membantu divisi terkait. Rekomendasi dari penelitian ini adalah restrukturisasi struktur organisasi pada PT. Matahari Department Store Tbk. agar menempatkan divisi IT sebagai divisi independen yang dapat mendukung kebutuhan berbagai divisi lainnya. Selain itu, rekomendasi yang selanjutnya adalah perlunya kebijakan baru dari pihak manajemen level atas PT. Matahari Department Store Tbk. untuk meningkatkan pengawasan dan alokasi investasi penggunaan teknologi informasi.

\subsection{Strategi SI/TI}

Strategi ini digunakan untuk mendukung strategi bisnis sistem informasi terkait teknologi yang digunakan PT. Matahari Department Store Tbk. untuk meningkatkan efisiensi dan efektifitas proses bisnis dalam meningkatkan laba dengan memberikan rekomendasi hardware, UI, database dan software

\subsection{Rencana Implementasi}

Rencana implementasi terdiri dari perencanaan jangka pendek dan jangka panjang. Perencanaan jangka pendek meliputi periode 1 sampai 2 tahun sedangkan pencanaan jangka panjang meliputi periode sampai dengan 5 tahun. Dalam penelitian ini direkomendasikan untuk implementasikan dalam jangka waktu 5 (lima) tahun. Rencana implementasinya dapat dilihat pada tabel 7.

Tabel 7. Rencana Implementasi SI Pada PT. Matahari Department Store Tbk.

\begin{tabular}{lccccc}
\hline Rekomendasi & 2021 & 2022 & 2023 & 2024 & 2025 \\
\hline Digital Marketing & $\mathrm{V}$ & & & & \\
Aplikasi Digital Signature dan Kuitansi Pegawai & $\mathrm{V}$ & & & & \\
Sistem Pendukung Keputusan Ukuran Baju & & $\mathrm{V}$ & & & \\
Sistem Informasi Integrasi Market Place & & & $\mathrm{V}$ & $\mathrm{V}$ & $\mathrm{V}$ \\
Sistem Informasi Integrasi Rantai Pasok & & & & & \\
Sistem Pendukung Keputusan Tren Fashion & & & & & \\
\hline
\end{tabular}

\section{KESIMPULAN}

Berdasarkan penelitian ini masih terdapat beberapa kesenjangan proses bisnis yang bisa didukung oleh sistem informasi untuk meningkatkan kinerjanya. Oleh sebab itu, direkomendasikan beberapa teknologi informasi untuk mendukung bisnis perusahaan, yaitu Digital Marketing, Aplikasi Digital Signature dan Kuitansi Pegawai, Sistem Pendukung Keputusan Ukuran Baju, Sistem Informasi Integrasi Market Place, Sistem Informasi Integrasi Rantai Pasok, Sistem Pendukung Keputusan Tren Fashion, Aplikasi Quality Control dan Sistem Informasi Kepatuhan. Rekomendasi yang dihasilkan dari penelitian ini diterapkan dalam jangka waktu 5 tahun, yakni 2021 hingga 2025. Selain itu PT. Matahari Department Store Tbk. perlu merombak struktur organisasinya dengan menempatkan divisi IT sebagai divisi independen dan menerapkan beberapa rekomendasi tren dibidang $\mathrm{TI}$.

\section{REFERENSI}

Ari Wedhasmara (2009) 'Langkah-Langkah Perencanaan Strategis Sistem Informasi Dengan Menggunakan Metode Ward And Peppard', Jurnal Sistem Informasi (JSI), 1(1), pp. 14-22. Available at: https://ejournal.unsri.ac.id/index.php/jsi /article/view/704.

Gazella, D., Darwiyanto, E. and Wisudiawan, G. A. A. (2016) 'Perencanaan Strategis Sistem Informasi Pada Industri Manufaktur Menggunakan Metode Ward and Peppard ( Studi Kasus: PT . Fin Komodo Teknologi)', in e-Proceeding of Engineering, pp. 5230-5237.

Gupta, A. (2013) 'Environmental \& PEST Analysis: An Approach to External Business Environment', International Journal of Modern Social Sciences, 1(2), pp. 34-43.

Gurel, E. and Tat, M. (2017) 'SWOT Analysis: A Theoretical Review', Journal of International Social Research, 10(51), pp. 
994-1006. doi: 10.17719/jisr.2017.1832.

Hakim, M. M. (2017) 'Information System Strategic Planning in IS / IT Service Provider', JIPI (Jurnal IImiah Penelitian dan Pembelajaran Informatika), 2(2), pp. 118127. doi: 10.29100/jipi.v2i2.395.

Himawan, P. A. and Astuti, T. (2017) 'Perencanaan Strategis Sistem Informasi Dan Teknologi Informasi Pemasaran Dan Pelayanan Pada Hotel (Studi Kasus : Grand Kanaya Baturraden)', Jurnal Pro Bisnis, 10(1), pp. 65-80.

Kaplan, R. S. and Norton, D. P. (1992) 'The Balanced Scorecard - Measures That Drive Performance', Harvard Business Review, p. 10.

Lah, A., Rahardja, Y. and Sitokdana, M. N. N. (2019) 'Perencanaan Strategis Sistem Informasi Menggunakan Metode Ward and Peppard Pada PT. Serasi Autoraya', Sebatik, 23(1), pp. 185-191.

Nurjaya, W. (2011) 'Model Strategic Planning For Information System Menggunakan Balance Scorecard Pada Universitas Komputer Indonesia Bandung', Majalah IImiah UNIKOM, 7(1), pp. 87-104.

Porter, M. E. (2008) 'The Five Competitive Forces
That Shape Strategy', Harvard Business Review, pp. 23-41.

Sammut-Bonnici, T. and Galea, D. (2015) 'PEST analysis', in Wiley Encyclopedia of Management. Chichester, UK: John Wiley \& Sons, Ltd. doi: 10.1002/9781118785317.weom120113.

Septiana, Y. (2017) ‘Perencanaan Strategis Sistem Informasi Dengan Pendekatan Ward And Peppard Model ( Studi Kasus : Klinik INTI Garut)', Jurnal Wawasan Ilmiah, 8(1), pp. 8-24.

Setiawan, H. S. (2016) 'Perencanaan Strategis Sistem Informasi PT.FM Guna Meningkatkan Daya Saing Menggunakan Metode Ward \& Peppard', STRING (Satuan Tulisan Riset dan Inovasi Teknologi), 1(2), p. 130 . doi: 10.30998/string.v1i2.1032.

Ward, J. and Peppard, J. (2002) Strategic Planning for Information Systems. 3rd edn. Baffins Lane, Chichester: John Wiley \& Sons.

Yulianto, E. (2018) 'Information System Strategic Planning Using IT Balanced Scorecard In Ward \& Peppard Framework Model', (August).

doi: 10.21817/ijet/2017/v9i3/170903134. 